\title{
DIASTOLIC PROPERTY OF LEFT VENTRICLE UNDER EXPERIMENTAL VOLUME OVERLOAD
}

\author{
SHUICHI NOMURA, M.D.
}

\begin{abstract}
Diastolic property of left ventricle (LV) was estimated by the passage of time using an experimental model of volume overload. Volume overload was surgically induced in dogs by means of bradycardia (complete A-V block). LV dimension and LV pressure were simultaneously recorded and pressurevolume curve (P-V curve) was obtained at the three stages, i.e., just after the creation of bradycardia; $8 \sim 14$ days after the operation; and $2 \sim 4$ months after the operation. The rightward shift of $\mathrm{P}-\mathrm{V}$ curve was confirmed as being associated with the development of eccentric hypertrophy; but this study showed no significant changes in indices of LV chamber elasticity. Indices of muscle elasticity derived from myocardial stress-strain $(\sigma-\epsilon)$ relationship also remained constant in the three stages.

It was demonstrated that the shift of the P-V curve resulted neither from the changes of LV chamber elasticity, nor myocardial elasticity.
\end{abstract}

C ARDIODYNAMIC characterization during the diastolic phase is understood to be an indispensable key to evaluation of the cardiac function. Recent theoretical evolution and clinical elaboration on cardiodynamics are remarkable. Changes in the diastolic property have been verified in several cardiac diseases. In ischemic heart diseases, 1,2 the loss of muscle elasticity due to myocardial ischemia causes an upward shift of the diastolic P.V curve. In the pressure-overloaded heart, ${ }^{3}$ decreased LV chamber elasticity occurs possibly from concentric hypertrophy itself. In a certain type of cardiomyopathy, 4,5 a change in the diastolic elastic property of LV plays an important pathophysiological role as reported in much of the literature. However, the diastolic property of the volume-overloaded heart is a problem still open to controversy. Cardiodynamics during the

\footnotetext{
Key Words:

Experimental volume overload

Diastolic elastic property

Complete A-V block

Pressure-volume curve
}

diastolic phase have not generally been as fully studied as during the systolic phase. Especially in the volume-overloaded heart, the coexistence of two factors, the volume and wall-thickness changes, extraordinarily complicates the analysis of the diastolic property. We have access to a number of studies documenting the diastolic property in volume overload. However, most of them seem to lack adequate evolution of the problem.

This paper describes the changes in the diastolic elastic property of LV as evaluated experimentally using a diastolic P.V relationship. The limited amount of P.V data previously documented is known to be inadequate. In the present investigation, therefore, the total diastolic P-V relationship was employed. Considering that the indices of chamber elasticity derived from the conventional concept of P-V relationship are not all unequivocal, we introduced other indices of the ventricular elastic property, i.e., muscle elasticity derived from the myocardial stress $(\sigma)$-strain $(\epsilon)$ relationship. In this study volume overload was surgically induced in dogs

(Received May 7, 1985; accepted February 13, 1986)

Second Department of Surgery Okayama University, Medical School, Okayama, Japan

Mailing address: Shuichi Nomura, M.D., Second Department of Surgery, Okayama University, Medical School, 2-5-1 Shikata-cho, Okayama 700, Japan 


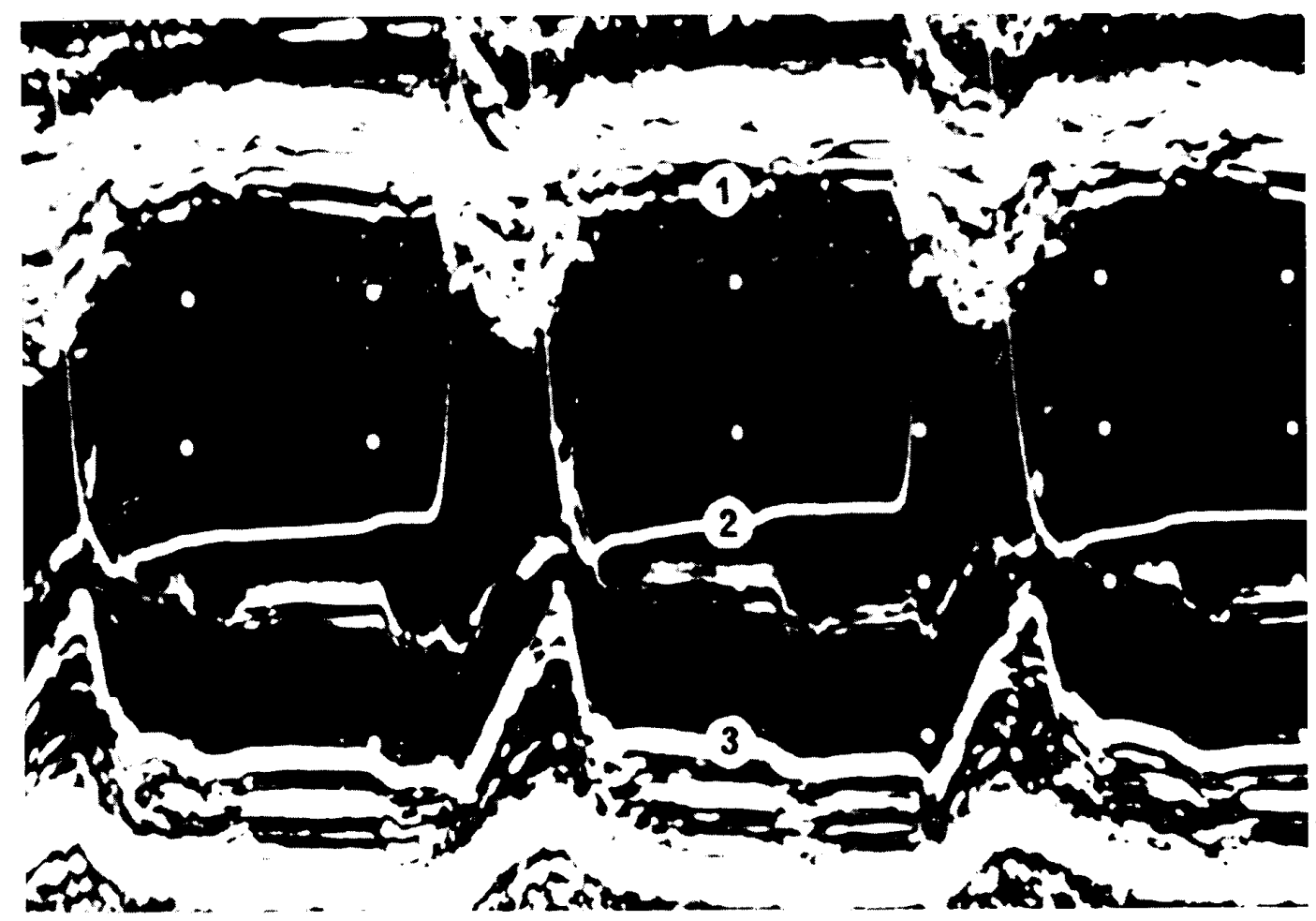

Fig.1. Simultaneous recording of LV dimension and pressure.

1: End-cardial echo of $L V$ anterior wall.

2: LV pressure.

3: End-cardial echo of LV posterior wall.

by means of bradycardia.

\section{MATERIALS AND METHODS}

\section{(1) Animal model}

Mongrel dogs weighing 7 19 kg were used for surgical preparation of the model. Under anesthesia with thiopental $(25 \mathrm{mg} / \mathrm{kg})$, the animals were endotracheally intubated and ventilated with a Harvard respirator. Right thoracotomy was performed at the level of the 5 th intercostal space. A small incision was placed to open the pericardium, and a purse string suture was made on the right atrium. Straight electrode was inserted in the atrial cavity through the purse string suture. Blind electrocauterization of the nodal region was performed by the method of MacDonald6 Complete A.V block was promptly obtained in most of the dogs within a brief time of cauterization, and the block rhythm continued throughout the observation period. Ventricular premature beats appeared frequently in several dogs on the day of the operation, but mostly disappeared on the following day. Brady. cardia was stable with a heart rate of $52 \pm 7 / \mathrm{min}$. No significant increase in the heart rate occurred except for a small amount of premature beats after exercise. The animals were housed in runs and freed from any planned exercise stress until experiment. The animals appeared seriously morbid and exhibited tachypnea and appetite loss three to five days after the operation. After approximately one week, the capacity for exercise and food consumption recovered in spite of continued bradycardia. The animals were observed for the maximum of 4 months. For measurements of the parameters, the animals were divided by pathological stage into the following three groups.

Group 1 (7 dogs): Measurements were made immediately after production of brady. cardia.

Group 2 (6 dogs): Measurements were made on complete recovery from morbidity $8 \sim 14$ days after the operation.

Group 3 (7 dogs): Measurements were made more than 2 months after the operation, on confirming the normal appetite and motor function without evidence of congestive heart failure.

(2) Instrumentation and measurement

Under anesthesia by intravenous injection of pentobarbital $(25 \mathrm{mg} / \mathrm{kg})$ and pancronium $(0.3$

Japanese Circulation Journal Vol. 5o, May 1986 
$\mathrm{mg} / \mathrm{kg}$ ), the trachea was intubated and connected to a Harvard respirator. Inspiratory oxygen concentration was constantly controlled throughout the experiment to maintain blood gas within a normal level. Measurements were carried out by the following procedures.

Cournand catheters $(7 \mathrm{~F})$ were inserted into the ascending aorta, inferior vena cava and left atrium through respective branches. A SwanGanz thermodilution catheter $(5 \mathrm{~F})$ was placed in the pulmonary artery. A Microtip transducer

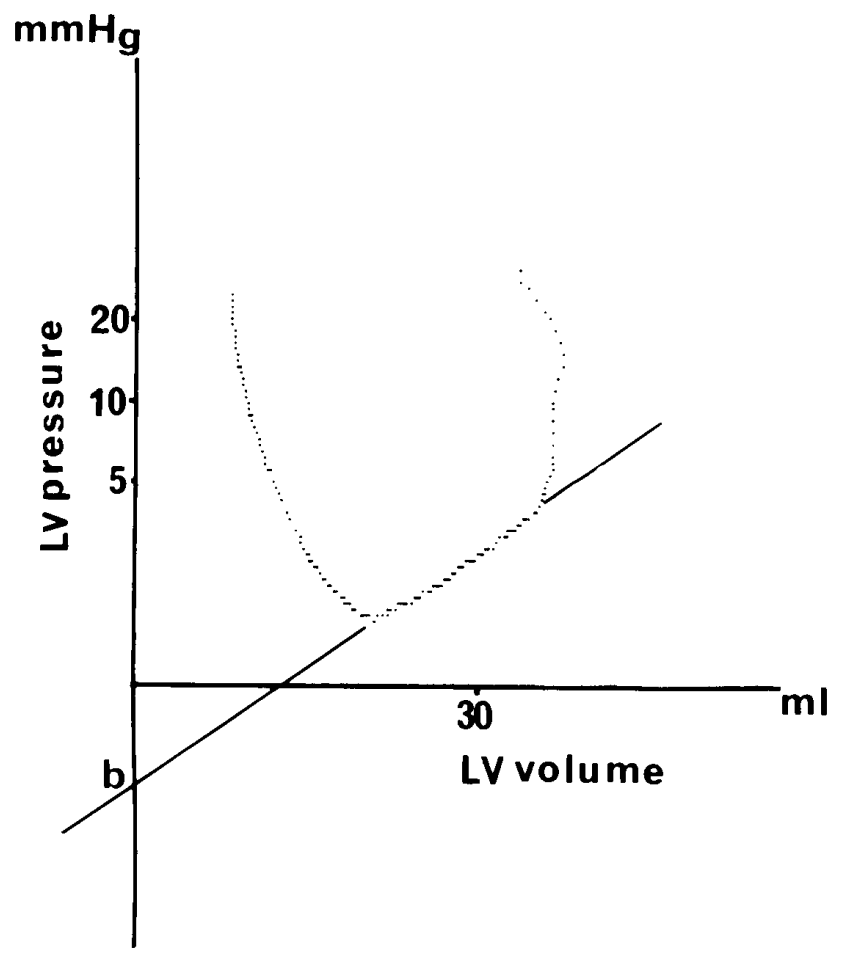

Fig.2. In (LV pressure)-volume relation in diastole, showing regression line drawn at the latter diastolic phase and its intercept " $b$ " to the pressure axis. catheter (Millar's Instruments, PC 370) was inserted into the left ventricular cavity by way of the aorta. The base line of the transducer was adjusted to atmospheric pressure before insertion. The tip of the catheter was placed in the mid LV cavity. Base line drift was detected by removing the catheter at the end of the measurement. Ultrasonic echocardiography was used for measurement of the left ventricular diameter and posterior wall thickness. A small-sized transducer probe (Toshiba Medical, $2.25 \mathrm{MHz}$ ) was attached to the epicardium of the right ventricular outflow region, and echocardiograms were recorded simultaneously with the left ventricular pressure trace (Fig. 1).

The hemodynamic measurement was made under the block rhythm. At necropsy, the heart was dissected into the left ventricular free wall, right ventricular free wall, interventricular septum and atrium by the Lewis' $\operatorname{method}^{7}$ and weighed. Cardiodynamic indices were derived from the data obtained from the dissected materials.

\section{(3) Data analysis}

Statistical significance of the differences was determined by t-test for the unpaired data and analysis of variance, and $p<0.05$ or $p<0.01$ were defined as significant. The results are expressed in terms of mean \pm SD.

The body surface area (BSA, in $\mathrm{m}^{2}$ ) was calculated by the equation 8 :

$$
\mathrm{BSA}=0.112 \cdot(\text { body weight }, \text { in } \mathrm{kg})^{2 / 3}
$$

(4) Cardiodynamic indices

1) LV weight and dimensions

TABLE I INDICES OF DIASTOLIC ELASTICITY FOR THREE GROUPS

\begin{tabular}{|c|c|c|c|c|c|c|c|c|c|c|c|c|}
\hline Group & & $\begin{array}{l}L V E D V I \\
\left(\mathrm{ml} / \mathrm{m}^{2}\right)\end{array}$ & $\begin{array}{c}L V / B W \\
(g / k g)\end{array}$ & $h / r$ & $\begin{array}{l}L V E D P \\
(m m H g)\end{array}$ & $\begin{array}{c}b \\
(m m H g)\end{array}$ & $K v$ & $\begin{array}{c}d V / d P \\
(m l / m m H g)\end{array}$ & $\begin{array}{c}d V / V \cdot d P \\
(L / m m H g)\end{array}$ & $\begin{array}{c}\sigma e d \\
\left(\mathrm{~g} / \mathrm{cm}^{2}\right)\end{array}$ & $K m$ & $E m$ \\
\hline$I$ & mean & 68.6 & 2.68 & 0.346 & 14.2 & 1.43 & 0.0652 & 1.205 & 0.0294 & 30.06 & 15.08 & 457 \\
\hline$n=7$ & $S D$ & 11.3 & 0.44 & 0.046 & 2.1 & 0.44 & 0.0191 & 0.406 & 0.0103 & 5.15 & 2.82 & 122 \\
\hline$I I$ & & $102.0^{* *}$ & 3.01 & $0.275^{*}$ & 15.5 & 1.11 & $0.0530^{*}$ & 1.398 & 0.0236 & 33.69 & 16.08 & 531 \\
\hline$n=6$ & & 15.4 & 0.52 & 0.042 & 1.4 & 0.80 & 0.0110 & 0.394 & 0.0033 & 2.35 & 1.94 & 61 \\
\hline$I I I$ & & $107.6^{* *}$ & $3.73 * *$ & $0.292^{*}$ & 13.1 & 1.01 & $0.0452 *$ & 1.770 & 0.0303 & 29.30 & 15.71 & 462 \\
\hline$n=7$ & & 19.0 & 0.67 & 0.023 & 2.0 & 0.54 & 0.0085 & 0.311 & 0.0099 & 4.94 & 2.28 & 105 \\
\hline
\end{tabular}

Abbreviations: $\quad L V E D V I=L V$ end-diastolic volume index; $L V / B W=L V$ free wall weight $/$ body weight; $h / r=L V$ wall thickness at end-diastole/LV end-diastolic dimension; $K v=$ slope of $\ln (L V$ pressure)-volume relationship; $d V / d P, d V / V \cdot d P=L V$ distensibility at end-diastole; $K m=$ stiffness constant derived from myocardial $\sigma-\epsilon$ relationship (see text in details); $E m=m u s c u l a r$ elastic stiffness at end-diastole (see text in details)

${ }^{*}$ Different from group I $p<0.05,{ }^{*}$ Different from group I $p<0.01$ 
LVEDVI

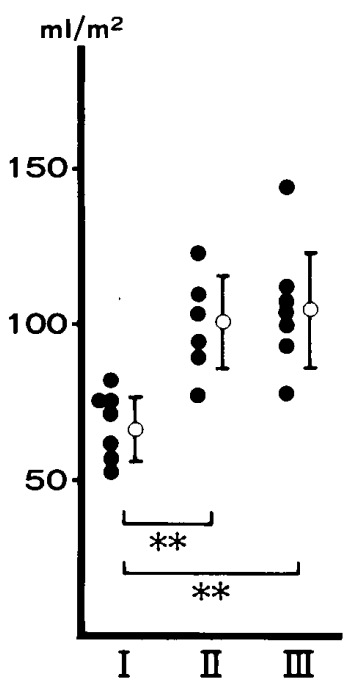

LV/BW

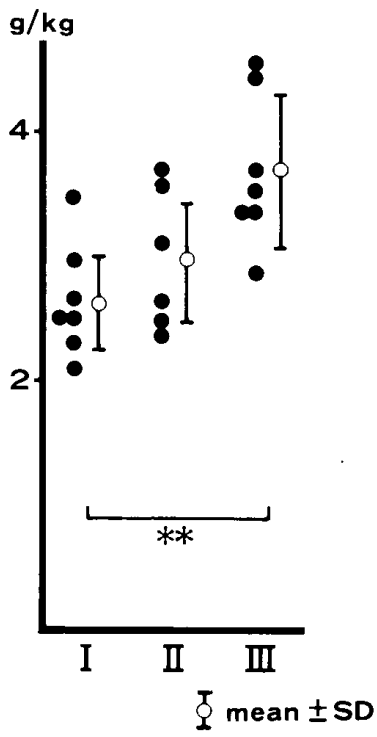

$\mathbf{h} / \mathbf{r}$

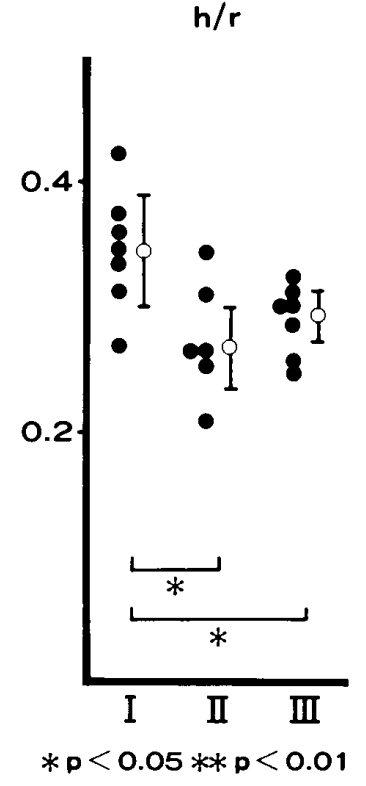

Fig.3. Changes in LV geometry during volume overload.

The changes in the heart weight were expressed in terms of the LV weight to body weight ratio $(\mathrm{LV} / \mathrm{BW})$. It was indicated that the echocardiographic measurement was apt to underestimate LV volume. In the present study, we applied Gibson's formula, which has less tendency to underestimate $\mathrm{LV}$ volume than other methods by single plane M-mode echocardiography. The LV wall thickness was measured and normalized by the LV diastolic dimensions.

2) LV diastolic wall stress ( $\sigma \mathrm{ed}$ )

The LV wall stress in the circumferential direction on the plane of the short axis was calculated by the formula proposed by Mirsky! ${ }^{10}$

$$
\text { oed }=\mathrm{P} \cdot(\mathrm{V} / \mathrm{Vw}) \cdot\left(1+\mathrm{n}^{3} / 2 \mathrm{R}^{3}\right)
$$

where $\mathrm{P}=\mathrm{LV}$ diastolic pressure, $\mathrm{V}=\mathrm{LV}$ volume, $\mathrm{Vw}=\mathrm{LV}$ wall volume (calculated as $\mathrm{LV}$ weight/ $1.050), \mathrm{n}=\mathrm{LV}$ internal radius and $\mathrm{R}=\mathrm{LV}$ midwall radius.

3) Parameters of diastolic elasticity

The LV pressure and dimensions were simultaneously recorded for analysis. The LV pressure curve and end-cardial echo of the anterior and posterior LV wall were individually traced and converted to digital data by a graphic digitizer (Nihon Koden K-510). Pressure-volume paired data were obtained with a digital computer Nihon Denki PC-8001mk2) at 2 msec intervals. Each LV pressure was logarithmically transformed, and the serial P.V data were presented on semi-logarithmic coordinates (Fig. 2). Early diastolic P.V relation does not necessarily confirm an exponential relation, because LV behaviour is influenced considerably by its viscous property during the rapid filling. The end-diastolic phase, believed to be nonexponential in the sinus rhythm, was applied in the present study owing to the absent end-diastolic atrial contraction in this model. The diastolic segment from the point located just after the nadir of the early diastolic pressure curve to the end-diastolic point was used in the present study. A straight regression line was drawn within this diastolic segment on the pressure (logarithmic scale)-volume plotted data. The passive elastic modulus $\mathrm{Kv}$ was indicated by the slope of the regression line, and $b$ was the interception with the regression line extrapolated to the pressure axis. Parameters indicating the LV elastic property were obtained by the following formula.

Passive elastic modulus ${ }^{11}$

$$
\mathrm{Kv}=(\ln \mathrm{P}-\ln \mathrm{b}) / \mathrm{V}
$$

End-diastolic compliance ${ }^{11}$

$$
\mathrm{dV} / \mathrm{V} \cdot \mathrm{dP}=(1 / \mathrm{Kv} \cdot \mathrm{P}) \cdot(1 / \mathrm{V})
$$

(Muscular) stiffness constant ${ }^{10}$

$$
\begin{aligned}
\mathrm{Km}= & 3 \cdot(1+\mathrm{Kv} \cdot \mathrm{V}) \cdot\left[1+(\mathrm{Vw} / \mathrm{V}) \cdot \mathrm{m}^{2} /\right. \\
& \left.\mathrm{m}^{2}+\mathrm{n}^{2}\right]
\end{aligned}
$$

(Muscular) end-diastolic elastic stiffness ${ }^{10}$

$$
\mathrm{Em}=\mathrm{Km} \cdot \text { oed }
$$

where $\mathrm{P}$ is an $\mathrm{LV}$ diastolic pressure, $\mathrm{V}$ an $\mathrm{LV}$ volume, $V w$ an $L V$ wall volume, $m$ an $L V$ external radius and $n$ an $L V$ internal radius. 


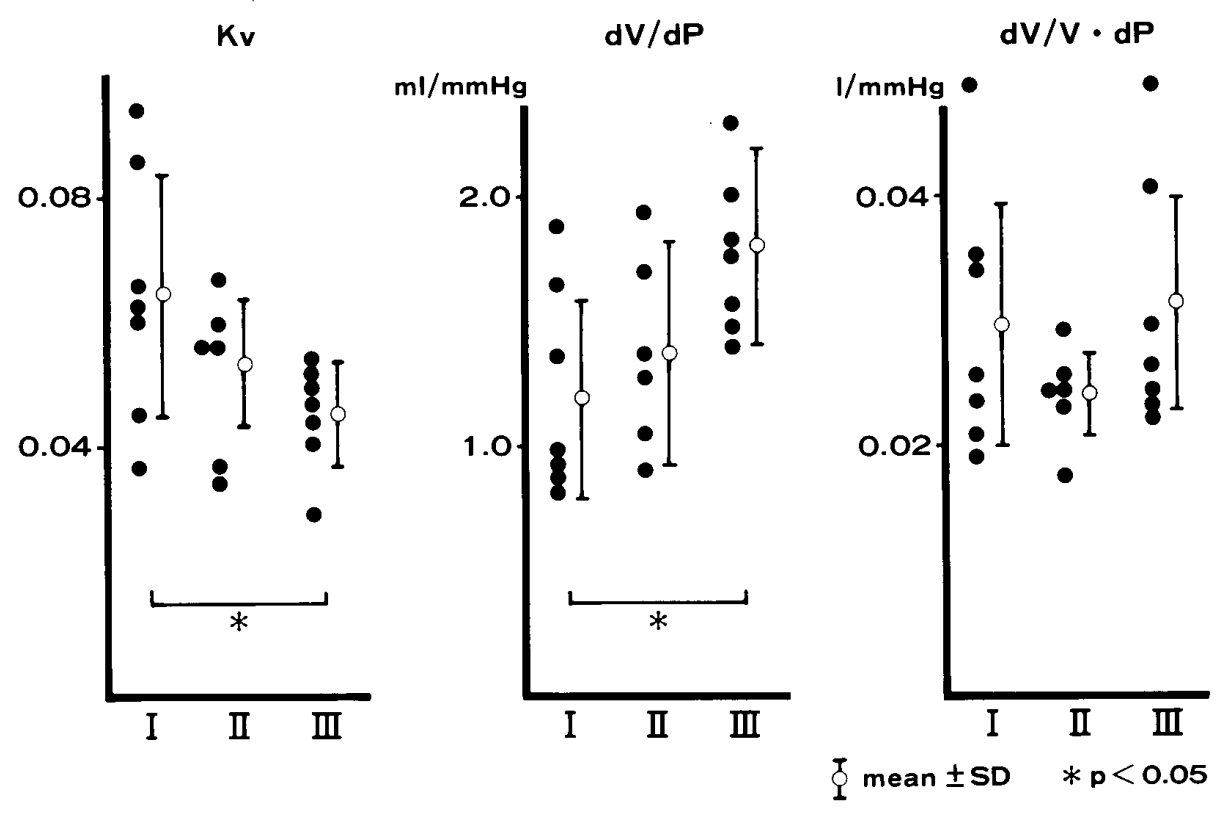

Fig.4. Changes in LV chamber elasticity during volume overload.
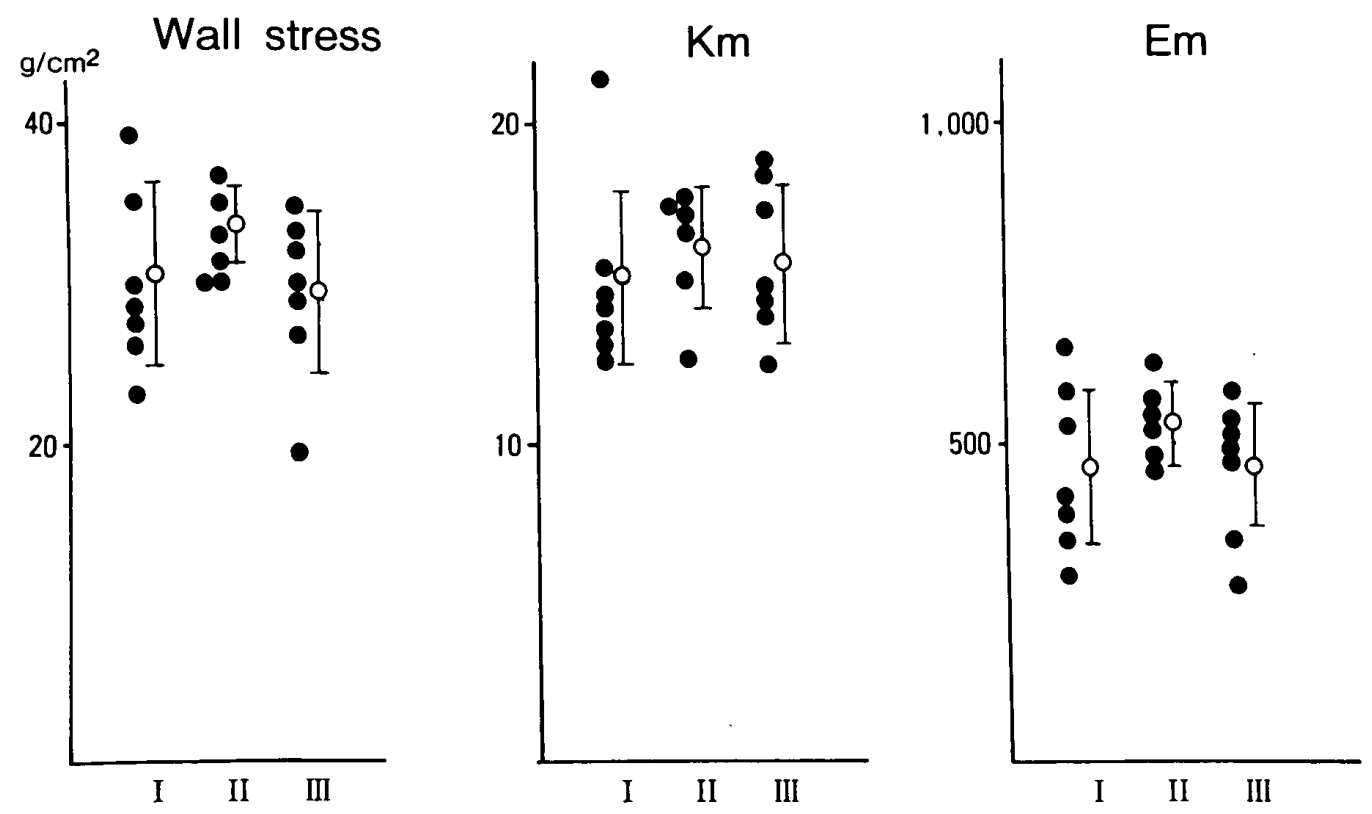

Fig.5. Changes in muscular elasticity of LV during volume overload.

\section{RESULTS (Table I)}

The hemodynamic data were obtained from the measurements under the block rhythm. The LV volume (LVEDVI) increased from $68.6 \pm$ $11.3 \mathrm{ml} / \mathrm{m}^{2}$ in group 1 to $102 \pm 15.4 \mathrm{ml} / \mathrm{m}^{2}$ in group 2 . In group 3 , it was approximately equal $\left(107.6 \pm 19.0 \mathrm{ml} / \mathrm{m}^{2}\right)$ to that in group 2 . The $\mathrm{LV}$ weight $(\mathrm{LV} / \mathrm{BW})$ tended to increase in group 2 $(3.01 \pm 0.50 \mathrm{~g} / \mathrm{kg})$ compared to group $1(2.68 \pm$ $0.48 \mathrm{~g} / \mathrm{kg}$ ), and markedly increased in group 3 $(3.73 \pm 0.67 \mathrm{~g} / \mathrm{kg})$. In terms of dimensional change, the LV wall thickness $(\mathrm{h} / \mathrm{r})$ was reduced in group $2(0.275 \pm 0.042)$, compared to group 1 $(0.346 \pm 0.046)$, but group $3(0.292 \pm 0.023)$ showed no definite change. Group 2 seemed to correspond to the stage when LV was dilated as a main compensatory reaction to volume overload, while group 3 to the stage when LV hypertrophy was added to LV dilatation (Fig. 3). Interception $b$ never stayed constant and was distributed over the range from $0.36 \mathrm{mmHg}$ to $2.48 \mathrm{mmHg}$ in the present investigation. Furthermore, interception $b$ did not differ among the 
three groups. The passive elastic modulus $\mathrm{Kv}$ of the chamber level decreased in sequence of the post-block pathological stage, namely, group 1 $(0.0652 \pm 0.0191)$, group $2(0.0530 \pm 0.0110)$ and group $3(0.0452 \pm 0.0085)$. The enddiastolic LV compliance $\mathrm{dV} / \mathrm{dP}$ increased in order of the post-block pathological stage, i.e., group 1 (1.205 \pm 0.406$)$, group $2 \quad(1.398 \pm$ $0.394)$ and group $3(1.770 \pm 0.311)$. However, when normalized by LVEDV, the $\mathrm{dV} / \mathrm{dP}$ change disappeared (Fig. 4). The stiffness constant $\mathrm{Km}$ as an index of the myocardial elasticity demonstrated no significant changes among the three groups, namely, group $1(15.08 \pm 2.82)$, group 2 $(16.08 \pm 1.94)$ and group $3(15.71 \pm 2.28)$. No significant differences were noted, therefore, in the elastic stiffness Em among the three groups (Fig. 5).

\section{DISCUSSION}

The LV diastolic property is recognized to be an indispensable key to understanding the cardiac function. The diastolic property has been approached mainly from the diastolic P.V relationship. Recent progress in the measuring technique and theories has allowed the analysis of $L V$ elastic property from $\sigma-\epsilon$ relationship. In previous reports, investigators elaborated various analytical methods for the estimation of $\mathrm{LV}$ chamber stiffness. These reports resulted in conflicting consequences. Pinski ${ }^{12}$ reported decreased stiffness of the chronic volume overload, but increased ventricular stiffness was reported by Gaasch.1 ${ }^{11}$ McCullagh ${ }^{13}$ observed constant LV chamber stiffness in the experimentally induced volume overload. In these studies, only limited parts of diastolic P-V relation were applied to their analysis. The evaluation of the diastolic property should be based on the total diastolic P.V relation.

A free cardiac muscle model ${ }^{14}$ has stimulated the formulation of the theory that the diastolic P.V relation follows a monoexponential equation even in working hearts. Indeed, only a certain segment of the diastolic phase deserves monoexponentiality in a resting condition. At present, approximation of the P.V curve to a monoexponential equation is accepted as a most appropriate theory for evaluation of the diastolic elasticity. Any segment of one diastolic P.V curve does not necessarily conform to the same exponential equation . $^{5}$ In fact, the equation applicable to each segment may accompany a certain difference if the segments are distant from each other. The P.V segments presented in this study were located near to each other, because the LV filling pressure was distributed within a relatively narrow range. Consequently, evaluation may gain higher accuracy in this investigation. A slope at the operating point in a $\mathrm{P}-\mathrm{V}$ curve, $\mathrm{dP} / \mathrm{dV}$, is affected by the position and slope of the P-V curve as well as the operating segment in the P-V curve. The $\mathrm{dP} / \mathrm{dV}$ value does not represent the same P-V curve or the identical ventricular elasticity. Appropriate normalization is needed for differentiation of each P-V curve. A perfect method for normalization of $\mathrm{dP} / \mathrm{dV}$ is still unavailable. Therefore, various methods for normalization have been evaluated by various investigators to suit their own designs. In chronic volume overloading, normalization by volume (or dimension) is inevitable for precise evaluation of $\mathrm{dV} / \mathrm{dP}$. In the present investigation, LVEDV, which had been prevalent formerly, was used for normalization. As a result, the differences in these parameters among the three groups disappeared after normalization by LVEDV. Evaluation of the elasticity by normalization of $\mathrm{dV} / \mathrm{dP}$ with $\mathrm{LV}$ dimensions or pressure proved to be an imperfect method for estimation of the chamber stiffness: $\mathrm{dV} / \mathrm{dP}$ (or $\mathrm{dP} / \mathrm{dV}$ ) does not delineate the whole P-V curve. Therefore, these indices should be interpreted to show merely the ventricular filling resistance at the operating point. The characteristics of each P.V curve may be presented more reasonably by $\mathrm{Kv}$ than $\mathrm{dV} / \mathrm{dP}$. Kv decreased in group 2 and 3 in order of the post-block pathological stage. A rightward shift of the P.V curve was predicted from the decrease in $\mathrm{Kv}$. Needless to say, $\mathrm{Kv}$ alone is not a sufficient parameter to indicate the ventricular stiffness and cannot be a determinant factor of the P-V curve unless " $b$ " is taken into account. To date, no proper parameter has been proposed in a combination of $\mathrm{Kv}$ and $\mathrm{b}$. The present investigation could not demonstrate the change in the chamber elasticity of LV in chronic volume overloading in spite of the definite shift of the P.V curve.

The myocardial elastic property is considered to be an important internal factor to regulate LV diastolic property excluding the relaxation property. Mirsky ${ }^{14}$ calculated the muscle elasticity constant $\mathrm{Km}$ from a single P.V point and demonstrated increased $\mathrm{Km}$ in clinical cases of chronic volume overload. However, Schwartz ${ }^{16}$ reported constancy of $\mathrm{Km}$ using a 
similar method in clinical cases. When determining $\mathrm{Km}$ from a single point, invariable " $\mathrm{b}$ " is essential. Mirsky and Schwartz selected 0.43 $\mathrm{mmHg}$ that had been proposed by Gaasch.

As demonstrated in this investigation, " $b$ " did not take a fixed value and frequently exceeded $0.43 \mathrm{mmHg}$. Therefore, Km presented by Mirsky may possibly take a higher value than that of this investigation. In estimation of the $\mathrm{LV}$ chamber elasticity, we should at least avoid oversimplification depending on a limited number of P-V data. Senda ${ }^{17}$ reported elevated $\mathrm{Km}$ on the basis of " $b$ " calculated in individual patients. Hess, ${ }^{18}$ applying a viscoelastic stress-strain model, reported unchanged $\mathrm{Km}$ in clinical cases of aortic regurgitation.

The present study demonstrated unchanged $\mathrm{Km}$ in the animals with chronic volume overloading. It does not stand to reason that $\mathrm{Km}$ stays constant in advanced stages of chronic volume overloading accompanied by a depressed cardiac function and long-standing morbidity. We should emphasize that significant eccentric hypertrophy does not necessarily result in $\mathrm{Km}$ elevation.

\section{Acknowledgements}

The author thanks Prof. S. Teramoto, Second Department of Surgery, Okayama University School of Medicine for his critical review. Thanks are also extended to Ass. Prof. Y. Senoo for his excellent guidance.

\section{REFERENCES}

1. MOMOMURA S, BRADLEY AB, GROSSMAN W: Left ventricular diastolic pressure-segment length relations and end-diastolic distensibility in dogs with coronary stenoses. Circ Res 55: 203, 1984

2. SHARMA B, BEHRENS TW, EREIN D, HODGES M, ASINGER RW, FRANCIS GS: Left ventricular diastolic properties and filling characteristics during spontaneous angina pectoris at rest. $A m J$ Cardiol 52: 704, 1983

3. PETERSON KL, TSUJI T, JOHNSON AD, LEWINTER M: Diastolic left ventricular pressurevolume and stress-strain relations in patients with valvular aortic stenosis and left ventricular hypertrophy. Circulation 58: 77, 1978

4. LORELL B, PAULUS W, GROSSMAN W, WYNNE J, COHN PF: Modification of abnormal left ventricular diastolic property by nifedipine in patients with hypertrophic cardiomyopathy. Circulation 65: 500,1982

5. GROSSMAN W, MCLAULIN LP, DOLLET EL: Alterations in left ventricular relaxation and compliance in congestive cardiomyopathy. Cardiovascu Res 13: 514, 1979

6. MACDONALD IB: A simple method of producing experimental heart block in dogs. J Thrac Cardiovascu Surg 13: 514, 1979

7. HERRMAN GR: Experimental heart disease 1. methods of dividing hearts; with sectional and proportional weights and ratios for two hundred normal dogs' hearts. Am Heart $J$ 1: 213, 1925

8. HOLT JP, ROHDE EA, KINES H: Ventricular volumes and body weight in mammals. Am J Physiol 215(3): H704, 1968

9. GIBSON DG: Estimation of left ventricular size by echocardiography. Br Heart J 35: 128, 1973

10. MIRSKY I, COHN PF, LEVINE JA, GORLIN R, HERRMAN MV, KREUREN TH, SONNENBLICK EH: Assessment of left ventricular stiffness in primary myocardial disease and coronary disease. Circulation 50: 128, 1974

11. GAASCH WH, BATTLE WA, OBOLER AA, BANAS JSJ, LEVINE HJ: Left ventricular stress and compliance in man with special reference to normalized ventricular function curves. Circulation 45: 746, 1972

12. PINSKI WW, LEWIS RM, HARTLEY CJ, ENTMAN ML: Permanent changes of ventricular contractility and compliance in chronic volume overload. Am J Physiol 237(5): H575, 1979

13. MCCULLAGH WH, COVELL JW, ROSS JJ: Left ventricular dilatation and diastolic compliance changes during chronic volume overloading. Circulation 45: 943, 1972

14. MIRSKY I, PARMLEY WW: Assessment of passive elastic stiffness for isolated heart muscle and the intact heart. Circ Res 33: 233, 1973

15. GLANTZ SA, PERMLEY WW: Factors which affect the diastolic pressure-volume curve. Circ Res 42: 171, 1978

16. SCHWARTZ F, FLAMENG W, SCHAPER J, HEHRLEIN F: Correlation between myocardial structure and diastolic properties of heart in chronic aortic valve disease. Am J Cardiol 42: 895,1978

17. SENDA S: Study on left ventricular diastolic properties of human heart by a combined method of echocardiography and catheter-tip manometry. J Jap Soc Intern Med 67: 17, 1978 (in Japanese)

18. HESS OM, SCHNEIDER J, KOCH R, BAMERT C, GRIMM J, KRAYENBUEHL HP: Diastolic function and myocardial structure in patients with myocardial hypertrophy, special reference to normalized viscoelastic data. Circulation 63: 360 , 1981 